\title{
Institutional Repository (IR) Awareness and Willingness of Faculty Staff to Deposit Research Work: A Study of Faculty Staff in Selected Public and Private University in Nigeria
}

\author{
Saturday U. Omeluzor \\ Collection Development and Systems Librarian, Library Department, Federal University of Petroleum Resources \\ Effurun, Delta State, Nigeria \\ Email: someluzor@yahoo.com
}

Received 1 November 2014; revised 9 December 2014; accepted 26 December 2014

Copyright (C) 2014 by author and OALib.

This work is licensed under the Creative Commons Attribution International License (CC BY). http://creativecommons.org/licenses/by/4.0/

(c) $\underset{\mathrm{EY}}{\mathrm{i}}$ Open Access

\section{Abstract}

This study appraised the awareness and willingness of faculty staff in Nigerian universities to deposit their pre and post research publications in open access institutional repository. Two universities (one private and one public) were systematically selected for the study. Nigeria has a total of 129 universities; 79 are public universities, while 50 are private universities. The researcher purposefully selected two universities from the public and private for convenience and easy analysis. The population of study cut across all faculty staff in the selected universities given a total number of 179 academic staff. Findings reveal that the majority of the respondents $(52 \%$ and $36 \%$ from private and public universities respectively) are aware of IR. Findings also show that the majority (62\% and $44 \%$ of the respondents in the private and public universities respectively) have published 1 - 10 research publications using materials from IR. While $22 \%$ and $26 \%$ of the respondents have also published up to 11 - 20 publications using materials published in IR. Unfortunately, despite benefitting from IR, findings reveal that $88 \%$ and $96 \%$ of the respondents from private and public universities have not deposited any publication in IR. The researcher, therefore, recommend that awareness of IR in institutions of higher learning must be prioritized and that faculty staff should be encouraged to contribute to IR project as a means of increasing their relevance, visibility and ranking and that of their affiliated university.

\section{Keywords}

Institutional Repository, Awareness, Willingness, Faculty Staff, Research, Private University, Public University, Library, Nigeria 


\section{Introduction}

One of the challenges that librarians face in the early years was to device viable means to manage, maintain, preserve and provide access to intellectual output and memoirs of their parent institutions. However, in this age, most libraries in collaboration with their parent institutions have taken roles in planning and building repositories thereby fulfilling their professional mandate of collecting, organizing, disseminating, preserving and providing access to information in digital format to library users [1]. That perhaps informed early librarians to create access and retrieval tools like catalogues, indexes and abstracts. These tools have their daunting limitations as researchers become increasingly anxious to access information at their fingertips. Therefore the need to be proactive to provide quick, adequate and accurate information within and beyond the library walls for effective teaching, learning and research.

Implementation of repositories that provides access to digital contents of an institution of higher learning is very important. It cannot be done in isolation of the faculty members who are stakeholder and key contributors. [2] opines that the main source for contents of any academic IR is the faculty members. It will be recalled that the potential value of IR is not yet fully appreciated by most faculty members in several universities especially in Nigeria. There is need for faculty members to be aware of the potentials and viability of IR. Many scholars have argued on issues relating to copyright as hindrance to effective implementation of IR in universities. To overcome the challenges of copyright, authors and publishers could agree for a dual copyright. In this regard, an author with copyrighted materials under dual agreement enjoys the right and privilege to retain the copyright to the same work that has been published by a journal [2].

Repository enhances access to institutional resources as well as increase visibility of a university. According to [3] the real strength of IR is in its ability to collect, preserve and display scholarly research of a university to the people in the community and beyond. According to [4], a repository is a place where information resources are stored and can be found. It is worthy to note that if nothing is kept in a repository, there will definitely be nothing to access or retrieve. IR captures, preserve and disseminate a university's collective intellectual capital as well serve as a meaningful indicator of an institution's academic quality.

Under the current system of scholarly communication, [5] opines that much of the intellectual output and value of an institution's intellectual property is diffused through thousands of scholarly journals. While faculty publications in journals reflects positively on the host university, an institutional repository concentrates on the intellectual product created by a university's researchers, making it easier to demonstrate its scientific, social and financial value.

In the context of this work, [6]'s definition of institution as a large and important organization such as a university or bank is suitable. As an important organization, employees and stakeholders would expect a lot to better their lot. One may wonder why it is important to assemble resources together and deposit them somewhere. It is usually such curios question that necessitates the creation of a repository. Institutional repositories (IRs) bring together all university's research under one umbrella, with the aim to preserve and provide access to those resources. [7] notes that IR is an excellent vehicle for working papers or copies of published articles and conference papers. Presentations, senior theses, and other works not published elsewhere can be published in the IR.

Observation and research have shown that despite the benefits of open access and institutional repositories, only few universities in Nigeria have embraced the project. Nigeria with more universities and several research institutes has very few repositories implemented. There was also indication of low level of awareness among authors, publishers and other stakeholders in Nigeria. A research by [2] shows that science, technology and medical discipline are more aware of IR while awareness among humanities academics is low. Premise on these assertions, it is necessary to ascertain if academic staff in Nigeria are aware of IR. What is the level of their preparedness to deposit their research findings to it is yet another question to answer.

\section{Research Questions}

This study attempt to answer the following questions: 
1) What is the level of awareness of faculty members about IR in Nigeria?

2) Are they willing to participate in IR?

3) What are their contributions to knowledge through IR?

4) What is the number of publication that is deposited in IR?

5) What are the benefits to deposit research article in IR?

6) What are the challenges that hinder depositing in IR?

\section{Literature Review}

An institutional repository is a digital system which captures and preserves the intellectual output of a single or multi-university community [7]. It is an avenue to publish which aim to reduce cost of scholarly publication and increase visibility and access of scholarly research from faculty and students of academic institution. [8] affirms that since IR captures, preserve and disseminates collective intellectual capital, it serves as a meaningful indicator of an institution's academic quality. This implies that research institutions like university is measured by the quality of publications made available and accessible to researchers world-wide. [8] further insists that IR increases visibility, reflects a high quality of scholarship; demonstrates value that can translate into tangible benefits including the funding from public and private sources that drives in part from an institution status and reputation. It means that ranking and recognition of academic institution is hinged on their research publication and visibility to the outer world. This claim is justifiable because, publications in IR are hosted by the university's website or third-party provider and published on the Internet. In other words, institutional repository is a sort of mirror image of print institutional archives, and in some academic institutions, it is being maintained by the institution's library [9].

According to [10] institutional repository consists of formally organized and managed collections of digital contents generated by faculty, staff, and students within an institution. A university based IR manages, disseminates, and preserve where appropriate, digital materials created by the institution and its community members. The main content of an academic IR is closely related to the academic research by staff and students in a university. Such contents include dissertations, journals, papers, technical reports, research projects, cooperating cases, creations, inventions, patents and student projects [11]. The contents can be available for integration with oncampus library and course management systems, and can also be made available to colleagues and students at other institutions, as well as to the general public [12].

In this digital era, [13] upholds that institutional repositories (IRs) play a vital role in protecting the informational output of academic activities for long-term access and posterity. To achieve an IR, the spotlight is not on technology, but on human activities that are served by technology. Furthermore, for librarians, the task can be exciting, challenging, and sometimes quite daunting. The skills required according to [5], range from a technical knowledge of information storage and retrieval techniques, to the latest approaches to metadata tagging, and to motivating reluctant faculty to meet their deadlines to submit needed documents.

An institutional repository is a more specific concept. [14] asserts that it is a centrally managed collection of institutionally-generated digital materials designed to be maintained in perpetuity. It is capable of capturing important information, indexing and serving a wide range of static and moving images, and be seamlessly visible from course management systems, integrated library systems, administrative workflow systems, and via public portals.

\subsection{Awareness of IR}

A common problem that most faculty members have is lack of awareness [2]. Most of them are bored with lots of academic work and do not have time to access regular publications about their institution nor realize to deposit in IR of their institution. However, a research by [10] indicates that most of the respondents were aware of IR. Result of their finding shows that $61.88 \%$ assistant professor, $24.38 \%$ associate professors and $7.5 \%$ Professor were aware of IR and their sources of awareness was through library professionals and their assistants, library website and manual, bulletin and periodicals and workshop, seminars and orientation programs among others.

\subsection{Benefits of IR to Higher Institution of Learning}

The benefit of IR is dual. It is beneficial to both the institutions and contributors that they affiliate with. ac- 
knowledges that open access institutional repositories are now globally accepted as one of the best model for scholarly communication. It has enormous benefits to the country, research scientists, scholars and information users in general. The need for institutional repository has come to limelight and cannot be overemphasized.

However, quite a number of institutions have realized the need to implement it. In Nigeria some academic institutions and libraries have implemented functional IRs. [15] in 2007 encouraged academic libraries to provide access to both print and electronic resources especially those generated within the university in order to increase access to information resources and visibility of their institutions as a measure of prestige and recognition internationally. [7] [8] [13] outline some benefits of IR.

1) It serves as tangible indicators of an institution's quality, thus increasing its visibility, prestige, and public value;

2) Increases the ranking of an institution both at local and international level;

3) Enhances learning, online teaching and research especially in higher institution of learning;

4) It presents an institution's intellectual capital to a whole lot of scholars;

5) It provides a central component in reforming scholarly communication by stimulating innovation in a disaggregated publishing structure;

6) It is an immediate and valuable complement to the existing scholarly publishing model, while stimulating innovation that evolve and improve over time;

7) It enhances resource sharing and provides long-term solution;

8) Remedying the weakness of self-archiving i.e. lack of proper security, long-term preservation, and wasting faculty time.

Furthermore, [7] appealed that as producers of primary research, academic institutions should take interest to capture and preserve the intellectual output of their faculty, staff, and students and deposit same in IR to support the university community.

Universities globally have been involved in this exercise whereby academic libraries are empowered to capture the intellectual contents of the university community for onward depository in IR, which enables students and researchers to access them. This therefore demand the cooperation of scholars to submit borne digital or analogue copies of their publications for digitization and proper formatting to internationally acceptable standard. Such resources could thereafter be uploaded in the university's repository for users to access anywhere and anytime.

There are numerous benefits that contributors are likely to enjoy including online access to articles without hindrance and charges, open access to a wider audience of researchers, increased impact of researcher's work, easy accessibility to research work and creation of further research approaches, self-archiving and increased citation to published scholarly work among others [10]. Furthermore, some motivating factors that should spur faculty members to contribute to IR include, quick dissemination, online indexing and archiving of material, increased public opinion, protection against plagiarism and publicity, publishing alongside other high quality research [10].

It has consistently been mentioned by several scholars that institutional repository captures and preserves the intellectual output of a university community with a view to exhibit contributors (authors) and university's visibility, prestige, international recognition, ranking, and winning of grants. Some of the documents to deposit according to [2] include journal articles, conference proceedings, theses and dissertations, technical reports, presentations among others. Indeed, IR is beneficial for academic award, professional recognition, accessibility and publicity. Perhaps, reasons why most contributors especially faculty members fail to deposit their intellectual contents may be attributed to lack of awareness.

\subsection{Factors to Consider for Effective Implementation of IR}

Implementation of a veritable IR requires a checklist of items to be involved in the process. Beside, a successful IR starts with a unique concept alongside dedicated personnel to accomplish tasks. Some of the factors to be considered according to [16] include:

1) Institutional culture: Institutional culture depends on how the organization is structured as well as how much collaboration and trust exists within an institution. In an academic institution, it is the culture of some faculty not to deposit their work on the repository. They need to be convinced and assured that contributing to a repository will enhance their reputations in their discipline and result in wider dissemination of their work; 
2) Scope of the repository: The promoter of a repository must first decide early the purpose and scope of the repository and communicate them to all affected parties;

3) Content: The institution must decide on how contribution can be made. Criteria for depositing into the repository could come from each community of users or from a central body with input from the participants. For example, the Dspace project at MIT include articles, reprints, technical reports, working papers, conference papers, e-theses, data sets, image files, audio and video files and reformatted digital library collections from members of the community;

4) Access level: Decision must be taken on whom to be allowed access to the contents of the IR and the level of usage;

5) Legal aspects: Libraries and administrators responsible for operating and maintaining repositories need to ensure that legal requirements are met. Such requirements include appropriate software and content licenses. A document to be signed by every contributor to grant permission to distribute and preserve materials must not be ignored;

6) Standards: Interoperability requires that repository employ standards developed to handle issues associated with open access. Such standards include

a) The Open Archival Information System (OAIS) Reference Model http://www.rig.org/longtermoasis.html;

b) Open Archives Metadata Harvesting Protocol (OAI-PMH);

c) The Metadata Encoding and Transmission Standard (METS);

7) Software: Software is a key element in the implementation of an IR. A simple guide to the version 2 of IR software published by the Open Access Society is a valuable tool for selecting software appropriate to the needs and context of an institution and its repository;

8) Sustainability: Maintenance and strategies to keep the IR running and to fulfill its purpose is essential. The administrator and all stakeholders must strive to achieve and sustain the purpose of implementing an IR;

9) Funding: Funding is an essential element to maintain an IR. Since most of the facilities for IR are capital intensive, adequate budgetary allocation is needed to maintain it.

In another dimension, a successful building of an IR repository involves eight " $\mathrm{C}$ " words which are comprehension, collaboration, context, change, caring, commitment, creativity and competence.

\subsection{What Constitutes Challenge to the Implementation of IR?}

Several factors pose challenge to successful implementation of IR in institutions of higher learning. Motivation and encouragement of major contributors, policy and understanding among professionals and their acceptance constitute some of the challenges. It is also observed that administrative attention and long term commitment to insure preservation and maintenance of the repository over time, providing the necessary confidence to enable faculty members to contribute their works to the repository is also a major challenge. Furthermore, assets management focused on developing metadata standards for digital objects, not excluding IT infrastructure and network architecture. According to [17], improved capabilities in the areas of rich media capture, ingestion and logging, providing ubiquitous and easy-to-use services to capture intellectual output that today is lost need to be considered. Another significant thing to consider is an acceptable policy statement for the management of digital rights.

Basically, funding the project may stand a cog on the wheel of progress if the key players are not carried along in the first instance. It is therefore very pertinent to seek approval from the university's management followed with persuasion and appeal for speedy take-off. In line with these, it is strongly recommended that libraries start the process with the Vice-Chancellor's or Provost's office from the beginning. [3] opines that

Successful IRs have the campus-wide support that comes from a committed stakeholder at the top. Your provost's office is essential to open doors for you to speak about the repository and to have others market it for you. With provost support, you'll likely have dean support as well and therefore faculty uptake.

Beside, identifying the vision, mission and goal that an IR was set to achieve is very necessary; however, derailing from such unique purpose may discourage stakeholders to contribute. Every institution has a vision and goal along with mission statement; therefore, for stakeholders to accept such laudable concept, IR goals must be aligned with the wider vision and goal of a university. 
Willingness to deposit publications into IR is an issue. According to [2], persuading the academics to deposit materials into IR is a challenge especially pre-published article. In their study, only $19.15 \%$ of the total respondents accepted to deposit as some of them complained of plagiarism and copyright issues.

\section{Methodology}

This study was to ascertain the awareness and willingness of faculty staff in two selected Nigerian universities to deposit their pre and post research publications in open access institutional repository. Two universities (one private and one public) were systematically selected for the study. Nigeria has 129 universities, among these, 79 are public university and 50 are private university. The researcher randomly selected one each from the public and private universities for convenience and easy analysis. Descriptive survey design was used. The population of study cut across all faculty staff in the selected universities given a total number of 179 academic staff. The sampling technique used was total enumeration; this involves the entire population of study. Questionnaire was the instrument used for data collection. 179 questionnaires were therefore administered on the respondents and 123 questionnaires were retrieved. Out of the 123 retrieved, 23 questionnaires were not properly answered, while 100 questionnaires were found usable from the two selected universities, which were used for the analysis. Data is presented in tables, frequency and percentage for clarity.

\section{Data Analysis and Findings}

Result in Table 1 shows that majority of the respondents, 53\% from private university and 60\% from public university are Masters Degree holders. It also indicates that $34 \%$ and $24 \%$ of the respondents from private and public universities respectively are Doctorate degree holders, while a lower percentage $14 \%$ and $16 \%$ of the respondents from private and public universities respectively are Bachelor degree holders. The B.Sc. holders are the lower level academics who are under the tutelage of their senior colleagues. Such level of academics is known as support staff in the academic department of a university.

Table 2 reveals that among the respondents, majority (88\%) from private and public universities respectively are aware of IR. This result corroborates the findings of [10] who found that majority (93.75\%) of the total respondents in their research are aware of IR. Result also shows that $70 \%$ are not aware while $42 \%$ of the respondents from private and public universities respectively are not sure about IR. This result substantiate with the

\begin{tabular}{ccccc}
\hline Table 1. Academic qualification of the respondents. & & \\
\hline & Private university & \multicolumn{2}{c|}{ Public university } \\
Current academic qualification & Frequency & $\%$ & Frequency & $\%$ \\
\cline { 2 - 5 } & 7 & 14 & 8 & 16 \\
Bachelor degree (B.Sc.) & 26 & 53 & 30 & 60 \\
Masters degree (M.Sc.) & 17 & 34 & 12 & 24 \\
Doctorate degree (Ph.D.) & 50 & 100 & 50 & 100 \\
\hline Total & & &
\end{tabular}

Table 2. Awareness level of institutional repository.

\begin{tabular}{|c|c|c|c|c|}
\hline \multirow{2}{*}{ Current academic qualification } & \multicolumn{2}{|c|}{ Private university } & \multicolumn{2}{|c|}{ Public university } \\
\hline & Frequency & $\%$ & Frequency & $\%$ \\
\hline Yes & 26 & 52 & 18 & 36 \\
\hline No & 15 & 30 & 20 & 40 \\
\hline Not sure & 9 & 18 & 12 & 24 \\
\hline Total & 50 & 100 & 50 & 100 \\
\hline
\end{tabular}


findings of [2] who noted that lack of awareness was a common problem that most faculty members have. This indicates that some of the respondents in this study are aware while some are not aware of IR and some are not sure.

Result in Table 3 indicates that $30 \%$ of the respondents in private university are ready to deposit their prepublished article, while $70 \%$ of the respondents from the private university are not ready and also not sure to do so. Result also shows that $54 \%$ of the respondents in public university are not interested with $34 \%$ of them that are not sure. This result substantiates the finding of [2] that persuading the academics to deposit their pre-published articles was a challenge. Finding in [2] research shows that only $19.15 \%$ of the respondents indicated interest to deposit their research work in IR.

Table 3 also reveals the willingness of the respondents in both private and public university to deposit their post-published articles in IR. Result shows that $78 \%$ and $75 \%$ of the respondents in private and public universities are willing to deposit their post published research work into IR. This result validates the findings of [2] whose finding indicates that majority of the faculty members in their study were ready to contribute their postpublished articles in IR.

Table 4 indicates that $30 \%$ of the respondents in the public university have not utilized IR resources to publish. Result also reveal that $62 \%$ and $44 \%$ of the respondents in private and public universities have $1-10$ publications, while $22 \%$ and $26 \%$ have $11-20$ publications through IR resources. This implies that majority of the respondents $62 \%$ and $44 \%$ in private and public universities respectively have $1-10$ publications. Result in Table 4 implies that resources from IR have helped majority of the faculty staff to contribute to knowledge.

The result in Table 5 shows that majority, $88 \%$ and $96 \%$ of the respondents from private and public universities respectively have not deposited any publication in IR. While only $10 \%$ and $4 \%$ have deposited $1-10$ publications in IR. This result may also be attributed to lack of awareness and their lack of willingness to deposit their research publication.

Result in Table 6 shows that majority of the respondents recognizes IR to have huge benefit that is capable to survive academic institution and to support scholars. The result reveals that $86 \%$ and $90 \%$ of the respondents agreed that IR provides open access to materials/research findings. Another majority, $88 \%$ and $96 \%$ of the respondents also accepted that IR contributes to knowledge. Result also reveal that $74 \%$ and $84 \%$ of the respondents in private and public university respectively accepted that it support institutional archives. This implies that the respondents are aware of the benefits of IR to scholars and institution. This result supports the findings of [7] and [13].

Result in Table 7 reveals that majority, $73.5 \%$ and $68 \%$ of the respondents from private and public universities agreed that issues about copyright are a hindrance to deposit research work in IR. To overcome copyright challenge, some open access publishers encourage authors to publish with them as they would be able to retain copyright of their article and have a choice of creative commons licenses [17]. Result also shows that majority of

\begin{tabular}{ccccc}
\hline Table 3. Willingness to deposit pre and post-published article in IR. \\
\hline $\begin{array}{c}\text { Willingness to submit } \\
\text { pre-published articles in IR }\end{array}$ & Private university & \multicolumn{2}{c|}{ Public university } \\
\cline { 2 - 5 } Yes & Frequency & $\%$ & Frequency & $\%$ \\
No & 15 & 30 & 6 & 12 \\
Not sure & 17 & 34 & 27 & 54 \\
Total & 18 & 36 & 17 & 34 \\
Willingness to submit & 50 & 100 & 50 & 100 \\
post-published articles in IR & Private university & Public university \\
\hline Yes & 39 & 78 & 15 & $\%$ \\
No & 2 & 4 & 0 & 0 \\
Not sure & 9 & 18 & 6 & 25 \\
Total & 50 & 100 & 50 & 100 \\
\hline
\end{tabular}


Table 4. Contribution to knowledge using publications in IR.

\begin{tabular}{ccccc}
\hline \multirow{2}{*}{$\begin{array}{c}\text { Number of publications } \\
\text { by respondents }\end{array}$} & \multicolumn{2}{c}{ Private university } & \multicolumn{2}{c}{ Public university } \\
\cline { 2 - 5 } & Frequency & $\%$ & Frequency & $\%$ \\
\hline None & 1 & 2 & 15 & 30 \\
$1-10$ publications & 31 & 62 & 22 & 44 \\
$11-20$ publications & 11 & 22 & 13 & 26 \\
21 and above & 7 & 14 & 0 & 0 \\
Total & 50 & 100 & 50 & 100 \\
\hline
\end{tabular}

Table 5. Publications deposited in IR by the respondents.

\begin{tabular}{ccccc}
\hline \multirow{2}{*}{$\begin{array}{c}\text { Publications deposited in } \\
\text { IR by respondents }\end{array}$} & \multicolumn{2}{c}{ Private university } & \multicolumn{2}{c}{ Public university } \\
\cline { 2 - 5 } None & Frequency & $\%$ & Frequency & $\%$ \\
\hline $1-10$ publications & 44 & 88 & 48 & 96 \\
$11-20$ publications & 5 & 10 & 2 & 4 \\
21 and above & 0 & 0 & 0 & 0 \\
Total & 1 & 2 & 0 & 0 \\
\hline
\end{tabular}

Table 6. Showing benefits of depositing research article to IR.

\begin{tabular}{|c|c|c|c|c|c|c|c|c|}
\hline \multirow{2}{*}{ Benefits } & \multicolumn{4}{|c|}{ Private University } & \multicolumn{4}{|c|}{ Public university } \\
\hline & Agreed & $\%$ & Disagreed & $\%$ & Agreed & $\%$ & Disagreed & $\%$ \\
\hline To provide open access to materials/research findings & 43 & 86 & 7 & 14 & 45 & 90 & 5 & 10 \\
\hline To preserve scholarly materials on campus & 37 & 74 & 13 & 26 & 42 & 84 & 8 & 16 \\
\hline To participate in the scholarly communication process & 37 & 74 & 13 & 26 & 38 & 76 & 12 & 24 \\
\hline Response to request from faculty & 18 & 36 & 32 & 64 & 24 & 48 & 26 & 52 \\
\hline To develop collaborative workspace/file sharing space & 30 & 60 & 20 & 40 & 36 & 72 & 14 & 28 \\
\hline To increase visibility of the institution & 30 & 60 & 20 & 40 & 34 & 68 & 16 & 32 \\
\hline To contribute to knowledge & 44 & 88 & 6 & 12 & 48 & 96 & 2 & 4 \\
\hline To support institutional archives & 37 & 74 & 13 & 26 & 42 & 84 & 8 & 16 \\
\hline
\end{tabular}

the respondents, $64 \%$ and $72 \%$ in private and public universities respectively identifies plagiarism as a challenge. This result is in line with the findings of [2] who report that majority of the respondents complained of plagiarism and copyright as a hindrance to deposit into IR. This is followed by lack of understanding of the goals of IR where $64 \%$ and $68 \%$ of the respondents respectively agree that it was a challenge. This entails that there is need for effective awareness about the benefits and positive impact of IR, policy against erring scholars who plagiarize to serve as deterrent to others and to have dual copyright of every document should also be prioritized.

\section{Discussion of Findings}

Findings in Table 2 reveal that majority of the respondents $88 \%$ from private and public universities respectively are aware of IR. This finding is in tandem with the findings of [10] who found that respondents in his research were aware of IR. However, findings indicated that $70 \%$ of the respondents from private and public universities 
respectively are not aware while $42 \%$ of the respondents from private and public universities respectively are not sure about IR. The implication of this finding is that most of the respondents are not aware and are not sure of the reasons for implementing IR. There is therefore, need for awareness and effective publicity in order to inform and educate the scholars who are major contributors about the benefits and impact of IR to an academic institution.

Findings in Table 4 reveal that $30 \%$ of the respondents in public university have not use any material from IR. Finding also shows that majority, $62 \%$ and $44 \%$ of the respondents in the private and public university respectively have published $1-10$ research publications using materials from IR. While another $22 \%$ and $26 \%$ of the respondents have also published up to $11-20$ publications using materials published in IR. This finding shows that while some are not aware of IR, majority who are aware have already contributed to knowledge using publications from IR. This finding confirms the finding of who acknowledges that open access institutional repositories are now globally accepted as one of the best model for scholarly communication. Findings in Table 4 further displays lack of commitment among academics especially in the public universities since finding reveal that none of the respondents has published from 21 publications and above.

Beside, findings in Table 4 show that respondents have published some good number of publications having utilized research published in IR. Unfortunately, findings in Table 5 reveal that $88 \%$ and $96 \%$ of the respondents from private and public universities have not deposited any publication in IR. This finding is discouraging which implies that the faculty staff who are major contributors to IR are not interested, nor willing to deposit their research works into IR.

Findings in Table 3 indicates that majority, $78 \%$ and $75 \%$ of the respondents from private and public universities are willing to deposit their post-publication but needs encouragement and persuasion. A university-wide awareness campaign, workshop and seminar could be a viable means to inform scholars about the impact and benefits of IR. In Table 3, the faculty members' willingness to deposit their post-publication was high while in the same Table 3, their willingness to deposit their pre-published publications is very low. Finding shows that $30 \%$ and $12 \%$ of the respondents from private and public universities respectively accepted to deposit their publication. The implication of this finding is that, IR projects in higher institutions of learning may lack quality pre-published research publications. The reaction of the faculty staff may be attributed to fear of plagiarism as shown in Table 7.

Finding in Table 7 reveal the challenges that hinder implementation of IR in most universities across Nigeria. Finding shows that majority $64 \%$ and $72 \%$ of the respondents in private and public universities respectively agreed that plagiarism is a challenge. Another majority, $73.5 \%$ and $68 \%$ of the respondents noted that copyright

\section{Table 7. Showing challenges to deposit in IR.}

\begin{tabular}{ccccccccc}
\hline \multirow{2}{*}{ Challenges to deposit in IR } & \multicolumn{3}{c}{ Private } & \multicolumn{3}{c}{ Public } \\
\cline { 2 - 8 } & Agree & $\%$ & Disagree & $\%$ & Agree & $\%$ & Disagree & $\%$ \\
\hline Funding & 25 & 50 & 25 & 50 & 22 & 44 & 28 & 56 \\
Plagiarism & 32 & 64 & 18 & 36 & 36 & 72 & 14 & 28 \\
Maintenance & 17 & 34 & 33 & 66 & 10 & 20 & 40 & 80 \\
Copyright issue & 36 & 73.5 & 13 & 26.5 & 34 & 68 & 16 & 32 \\
Lack of incentive & 28 & 56 & 22 & 44 & 18 & 36 & 32 & 64 \\
Lack of will to deposit & 21 & 42 & 29 & 58 & 24 & 48 & 26 & 52 \\
No appropriate agreement & 29 & 58 & 21 & 42 & 10 & 20 & 40 & 80 \\
Poor IT infrastructure development & 29 & 58 & 21 & 42 & 25 & 50 & 25 & 50 \\
Long term commitment of contributors & 25 & 50 & 25 & 50 & 14 & 28 & 36 & 72 \\
Lack of understanding of the goals of IR & 32 & 64 & 18 & 36 & 34 & 68 & 16 & 32 \\
Lack of understanding among stakeholders & 21 & 42 & 29 & 58 & 20 & 40 & 30 & 60 \\
Lack of Administrative attention and support & 25 & 50 & 25 & 50 & 16 & 32 & 34 & 68 \\
\hline
\end{tabular}


was a problem while $64 \%$ and $68 \%$ of the respondents from private and public universities respectively also agreed that lack of understanding of the goals of IR was a challenge. These challenges hinder the implementation and eventual take-off of IR projects in most universities across Nigeria.

Although, funding of IR projects seem not to be a major challenge as it came 5th in rank among the challenges. However, it is important to ensure that fund is made available since implementation of IR is usually capital intensive. Lack of understanding of IR goal requires effective and aggressive awareness campaign, education and persuasion. Plagiarism requires adequate policy and strengthening of ownership right agreement and enforcement.

\section{Conclusions}

The need for institutional repository as a tool to provide access to faculty staff's intellectual research publications and digital contents of a university is very important. This is to enhance visibility, recognition collaboration and dissemination of information. Most faculty staffs and universities are yet to realize and recognize the potentials of IR. Despite the fact that some researchers have benefited and enjoyed access to IR contents of other universities, many faculty staffs find it difficult to deposit their pre-publication in IR.

There are numerous academic institutions all over the world today that are emphasizing the need to create repositories and open access to quality peer reviewed articles in order to make information freely accessible.

Evidence-based researches have proved that IR is a pride of every academic library and its parent institution. Libraries have a duty to implement IR and create awareness for faculty staff to deposit their research findings. Hence, demand for access to quality research publications is increasing, and there is also a need for the libraries and universities to take proactive steps to plan and implement tools that will meet the informational needs of potential library clients.

\section{References}

[1] Drake, M.A. (2004) Institutional Repositories: Hidden Treasures. Vol. 12, Information Today. www.infotoday.com

[2] Dutta, G. and Paul, D. (2014) Awareness on Institutional Repositories-Related Issues by Faculty of University of Calcutta. Journal of Library and Information Technology, 34, 293-297. http://dx.doi.org/10.14429/djlit.34.5138

[3] Bepress (2009) Making the Case for an Institutional Repository to Your Provost. http://works.bepress.com/cgi/viewcontent.cgi?article=1027\&context=ir research

[4] Cambridge Advanced Learner's Dictionary. http://dictionary.cambridge.org/dictionary/british/repository

[5] Johnson, R.K. (2002) Institutional Repositories: Partnering with Faculty to Enhance Scholarly Communication. D-Lib Magazine, 8. http://www.dlib.org/dlib/november02/johnson/11johnson.html

[6] University of Nebraska, Lincoln (2013) About Institutional Repositories. http://digitalcommons.unl.edu/about.html

[7] Crow, R. (2002) The Case for Institutional Repositories: A SPARC Position Paper. Scholarly Publishing \& Academic Resources Coalition, Washington DC. http://www.arl.org/sparc/bm doc/ir_final_release_102.pdf

[8] Sharma, A.K., Meichieo, K. and Saha, N.C. (2008) Institutional Repositories and Skills Requirements, a New Horizon to Preserve the Intellectual Output: An Indian Perspective. http://ir.inflibnet.ac.in/bitstream/1944/1145/1/30.pdf

[9] Anunobi, C.V. and Okoye, I.B. (2008) The Role of Academic Libraries in Universal Access to Print and Electronic Resources in the Developing Countries. http://www.webpages.uidaho.edu/ mbolin/anunobi-okoye.htm

[10] Dhanavandan, S. and Tamizhchelvan, M. (2013) A Critical Study on Attitude and Awareness of Institutional Repositories and Open Access Publishing. Journal of Information Science Theory and Practice, 1, 67-75. http://dx.doi.org/10.1633/JISTaP.2013.1.4.5

[11] Chuang, C.F. and Cheng, C.J. (2010) A Study of Institutional Repository Service Quality and Users' Loyalty to College Libraries in Taiwan: The Mediating \& Moderating Effects. Journal of Convergence Information Technology, 5, 89-99.

[12] EDUCAUSE (2003) Institutional Repositories: Enhancing Teaching, Learning, and Research. http://net.educause.edu/ir/library/pdf/DEC0303.pdf

[13] Murray, A. (2008) What We Talk about When We Talk about Institutional Repositories. http://library.concordia.ca/about/staff/forum/What We Talk About When $\% 20 \mathrm{We}$ Talk About.pdf

[14] McCord, A. (2003) Institutional Repositories: Enhancing Teaching, Learning and Research. http://net.educause.edu/ir/library/pdf/dec0303.pdf 
[15] National Universities Commission (2007) Webometric Ranking of World Universities. Monday Bulletin, 2, 1-7.

[16] Rao, P.V. (2007) Institutional Repositories: A Key Role Forlibraries. 5th International CALIBER, Chandigarh, 8-10 February 2007, 689-695. http://ir.inflibnet.ac.in/bitstream/1944/1443/1/689-695.pdf

[17] Wiley Online Library (2014) Online Open: Copyright and Open Access Licenses. http://olabout.wiley.com/WileyCDA/Section/id-406241.html?dmmsmid=88936\&dmmspid=19838560\&dmmsuid=233 $\underline{7947}$ 